\title{
Thymectomy for myasthenia gravis
}

\author{
F. RONALD EDWARDS and ANDREW WILSON
}

\begin{abstract}
Liverpool Cardio-thoracic Surgical Centre, Broadgreen Hospital and Clinical Pharmacology Unit, Whiston Hospital, and Department of Pharmacology and General Therapeutics, Liverpool University
\end{abstract}

\begin{abstract}
Between 1951 and 1971 thymectomy was performed on 41 patients with myasthenia gravis. They were selected from a total group of 95 myasthenic patients receiving anticholinesterase therapy. The criteria for selecting patients for thymectomy and the assessment of their progress after operation are described. All the patients have been examined by us at intervals and the results of this follow-up are presented. The survey has shown that substantial improvement after thymectomy occurred in 21 patients (group A), seven of whom had complete remissions without medication for periods of up to 12 years after operation. Considerable benefit from the operation was also observed in seven patients (group B); although their response was less spectacular, in that their daily requirement of anticholinesterase drugs was not changed, their functional activities were significantly enhanced. The most favourable results were seen in female patients aged 15 to 40 years, six of whom had one or more successful pregnancies. Thymectomy did not improve the general condition or progress of six patients (group C). There were three deaths within 16 days of operation, and two patients died within one year. Eight patients survived for periods of 3 to 16 years; six of these died from causes other than directly from myasthenia, and two died at home without established cause.
\end{abstract}

Thymectomy for myasthenia gravis still seems to be considered one of the more controversial surgical operations. Since attention was first drawn to this subject in a preliminary report by Blalock and his colleagues (1941) a number of reports have been published during the past 30 years. The conflicting conclusions between the results notably of Keynes in England (1949, 1954), reviewed by Ross (1952) and Simpson (1958), and those reported from America by Eaton and Clagett $(1950,1955)$ and by Grob (1953) were discussed by Osserman (1958) and later by Viets and Schwab (1960), who considered that thymectomy, when properly carried out on selected patients, offered the best chance for a complete and possibly permanent remission from myasthenia gravis. With the accumulating experience of a more precise dosage of anticholinesterase drugs and improvements in pre- and post-operative management, there appears to be less diversity of opinion about the value of thymectomy. Thus Perlo et al. (1966) in Boston and New York found complete remission or substantial improvement after thymectomy in $84 \%$ of 45 female patients with severe myasthenia, while in Los Angeles Buckberg, Herrmann, Dillon, and Mulder (1967) considered, in a review of 48 patients, that the most favourable results were in females with symptoms of less than six years dura- tion. A recent further review by the former authors of 217 female and 50 male patients showed that $78 \%$ of females and $68 \%$ of males obtained a satisfactory result from surgical treatment (Perlo et al., 1971). These authors considered thymectomy to be a highly effective method of treatment for myasthenia gravis and that patients selected from the first to the sixth decades with a duration of symptoms of five or more years may benefit from the operation.

\section{DEFINITION AND CLASSIFICATION}

A follow-up has been made of 41 patients with myasthenia gravis operated upon in Liverpool between 1951 and 1971 .

AGE AND SEX Table I shows that 32 female and 9 male patients were subjected to thymectomy.

\section{T A B LE I}

41 PATIENTS WITH MODERATE OR SEVERE GENERALIZED MYASTHENIA GRAVIS

\begin{tabular}{l|c|c|c|c|c|c|c}
\hline & \multicolumn{5}{|c|}{ Age Group (yr) } & Total \\
\cline { 2 - 8 } & $12-20$ & $21-30$ & $31-40$ & $41-50$ & $51-60$ & $61-70$ & \\
\hline $\begin{array}{l}\text { Female } \\
\text { Male }\end{array}$ & 10 & 8 & 6 & 5 & 3 & 0 & 32 \\
\hline Total & 13 & 9 & 8 & 6 & 4 & 1 & 41 \\
\hline
\end{tabular}


Thirteen patients were less than 21 years of age and five were 51 years or more ; the majority of patients (23) were within the age range of 21 to 50 years.

CLINICAL FEATURES All the patients had signs and symptoms characteristic of generalized myasthenia, involving both craniopharyngeal and limb muscles; 10 patients had on one or more occasions attacks of severe respiratory distress. No patients with ocular involvement only were offered thymectomy.

Using a clinical classification based on the features described by Osserman (1958), the patients before operation were distributed within the categories shown in Table II. The duration of symptoms ranged from six months to 15 years. The Figure shows that the majority of patients $(85 \%)$ had symptoms lasting from within six months to

\section{T A B LE II}

CLINICAL CLASSIFICATION BEFORE THYMECTOMY

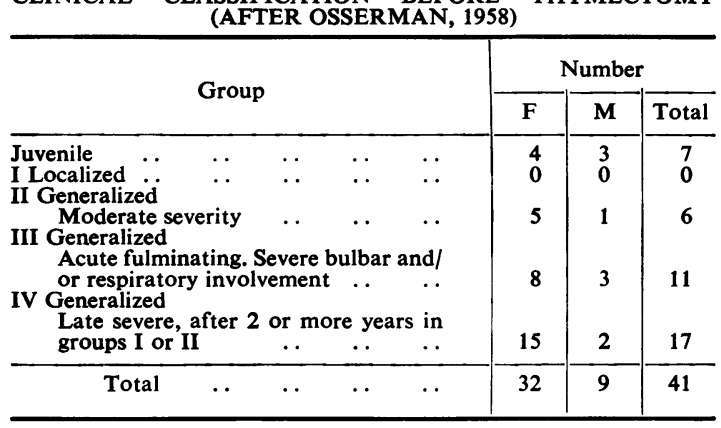

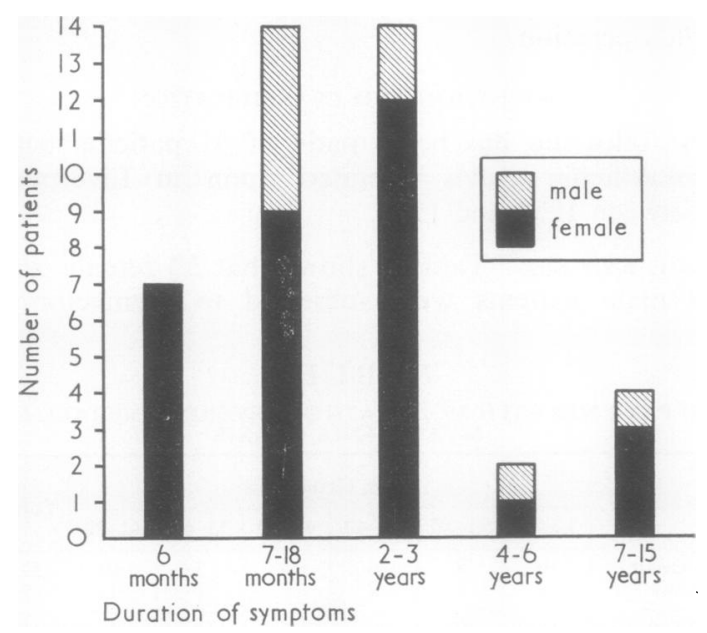

FIGURE. Duration of symptoms before thymectomy. three years before operation. All patients had been $\frac{\vec{C}}{\bar{C}}$ treated with either neostigmine (Prostigmin), $\frac{\bar{c}}{\bar{c}}$ $15 \mathrm{mg}$, or pyridostigmine (Mestinon), $60 \mathrm{mg}$, or $\overrightarrow{\widetilde{\Phi}}$ both, usually by oral dosages ranging from 6 to $\varrho$ 90 tablets daily. Eight patients required intra- $ळ$ muscular injections of neostigmine in addition to $\vec{\circ}$ oral medication.

INDICATIONS FOR THYMECTOMY The selection of patients for operation was based on several criteria, $\vec{x}$ of which the most important are the following: iv (a) considerable weakness and incapacity despite or anticholinesterase therapy ;

(b) recurring respiratory infection leading to one 은 or more incidents of myasthenic or cholinergic $\vec{B}$ crisis ;

(c) recently married women with prospective hopes of children.

It was hoped that, by removing the thymus gland, alleviation of symptoms would be complete $\vec{\theta}$ or, if not, a new and more effective balance of $N$ anticholinesterase drugs could be obtained. No patient had a demonstrable tumour preoperatively, but in six, at operation an encapsulated area, varying in size from 0.5 to $3 \mathrm{~cm}$ in diameter, was \% found, which could be called a 'thymoma' but $\stackrel{\varnothing}{\unrhd}$ which histologically showed no difference in struc- $\overrightarrow{\vec{P}}$ ture or activity from the main thymus gland.

Thymectomy was performed through a median sternotomy and a complete removal of the thymus was performed in all cases. The pre- and postoperative management of these patients will be reported elsewhere.

\section{RESULTS}

ASSESSMENT OF RESPONSE TO THYMECTOMY The periodic assessment of patients was based on the classification systems used by Keynes (1949) and modified by Ross (1952) and by Simpson (1958). $\frac{D}{O}$ Three categories were used: group A-substantial benefit with no medication or significantly less $N$ than before operation; Group B-considerable N benefit with the same or a similar daily dosage of anticholinesterase drugs; Group C-no improvement or worse. For the present purpose all patients were classified in categories at intervals beginning one year after operation.

The results of the survey are summarized in Table III.

Group $A$ : Substantial benefit This group consists of 21 patients who substantially benefited from $\stackrel{\square}{\mathbb{Q}}$ thymectomy in as much as they all had greatly 
increased functional activity whereby they resumed full-time work or household duties and were able to engage in general social activities. Seven of these patients have had complete remissions without medication for periods of up to 12 years after thymectomy (Table IV) ; 14 patients have continued to take anticholinesterase drugs in much smaller daily doses than before operation. Since thymectomy six patients have had one or more successful pregnancies, resulting in 10 normal healthy babies (Table V).

Two women aged 55 and 58 years died 4 and 10 years, and two men aged 14 and 49 died 3 and 16 years after thymectomy, from causes not directly associated with myasthenia. These patients are also included in Table VII.

Group B : Some benefit This group consists of seven patients whose functional activity was substantially enhanced but required medication with a daily dosage similar to the preoperative levels. Three of these patients, who died three, six and nine years after operation, are included in Table VII.

T A B L E I I I

PROGRESS OF 41 PATIENTS AFTER THYMECTOMY

\begin{tabular}{|c|c|c|c|}
\hline & Total & $\mathbf{F}$ & $\mathbf{M}$ \\
\hline $\begin{array}{l}\text { Substantial benefit (A) } \\
\text { Some benefit } \\
\text { No benefit or worse (C) } \\
\text { Not yet assessed } \\
\text { Died within } 16 \text { days }\end{array}$ & $\begin{array}{r}21 \\
7 \\
6 \\
4 \\
3\end{array}$ & $\begin{array}{r}19 \\
5 \\
3 \\
3 \\
2\end{array}$ & $\begin{array}{l}2 \\
2 \\
3 \\
1 \\
1\end{array}$ \\
\hline
\end{tabular}

T A B L E I V

PATIENTS WITH COMPLETE REMISSIONS

\begin{tabular}{l|c|c|c}
\hline Sex & $\begin{array}{c}\text { Age at } \\
\text { Operation } \\
\text { (yr) }\end{array}$ & $\begin{array}{c}\text { Time Since } \\
\text { Thymectomy } \\
\text { (yr) }\end{array}$ & $\begin{array}{c}\text { Consecutive } \\
\text { Period Without } \\
\text { Medication } \\
\text { (yr) }\end{array}$ \\
\hline F & 35 & $15 \cdot 5$ & 9 \\
F & 39 & 13 & 12 \\
M & 33 & 13 & 10 \\
F & 19 & 7 & 5 \\
F & 19 & $3 \cdot 5$ & 3 \\
F & 20 & 3 & 2 \\
\hline
\end{tabular}

T A B L E V

PATIENTS WITH BABIES BORN AFTER THYMECTOMY

\begin{tabular}{c|c}
$\begin{array}{c}\text { Age of Mother at Operation } \\
(\mathrm{yr})\end{array}$ & Baby Born After Operation \\
$(\mathrm{yr})$
\end{tabular}

Group C : No improvement or worse Six patients did not derive any notable benefit from thymectomy. This group consists of three female patients, one of whom died within one year, and three males, two of whom died one and five years after operation.

Not assessed Four patients (three female and one male) who had thymectomies less than one year before the present survey have not yet been assigned a category.

Operative mortality Three patients died within 16 days after operation (Table VI).

Late deaths A summary is given in Table VII of 10 patients who died at stated intervals after operation. Two died within one year, and eight survived for periods of 3 to 16 years; it is known that six of the latter died from causes other than directly from myasthenia and two died at home without established cause.

T A B LE VI

OPERATIVE MORTALITY

\begin{tabular}{|c|c|c|c|}
\hline Sex & Age & Cause & $\begin{array}{l}\text { Time After } \\
\text { Operation } \\
\text { (days) }\end{array}$ \\
\hline $\begin{array}{l}\mathbf{F} \\
\mathbf{F} \\
\mathbf{M}\end{array}$ & $\begin{array}{l}12 \\
50 \\
32\end{array}$ & $\begin{array}{l}\text { Bronchopneumonia } \\
\text { Pulmonary embolism } \\
\text { Staphylococcal pneumonia }\end{array}$ & $\begin{array}{l}11 \\
16 \\
14\end{array}$ \\
\hline
\end{tabular}

T A B LE VII

LATE MORTALITY OF 10 PATIENTS AFTER THYMECTOMY

\begin{tabular}{l|c|c|c}
\hline & \multicolumn{2}{|c|}{ Period after Operation (yr) } \\
\cline { 2 - 3 } & 1 or Less & $3-4$ & $5-16$ \\
\hline $\begin{array}{c}\text { Age at death (yr) } \\
\text { Female } \\
\text { Male }\end{array}$ & $(12)$ & $\begin{array}{c}(23),(59) \\
(17)\end{array}$ & $\begin{array}{c}(47),(50),(68) \\
(24),(65)\end{array}$ \\
\hline Total no. & 2 & 3 & 5 \\
\hline
\end{tabular}

\section{DISCUSSION}

The results of this review are in general agreement with those more recently published by Perlo and his colleagues (1971). In the present survey, in which only 9 male patients were studied compared with 32 female patients, it is not possible to make any valid conclusions about the relative prospects of thymectomy in male and female patients. We are particularly convinced of the beneficial effects of the operation in women in the age groups of 15 to 40 years and of the successful return of these 
patients to normal household activities including those of rearing children. Many of these patients have also resumed full-time or part-time work. Their response to anticholinesterase drugs was substantially more effective than before operation and there was less fluctuation in symptoms and daily dosage. Moreover they were better able to cope with intercurrent infections such as colds and coughs and none had any recurrence of myasthenic or cholinergic crisis. Although the majority of patients have been operated on within three years of the onset of myasthenic symptoms, in three patients who had substantial benefit (group A) the duration of the disease before operation ranged from 6 to 14 years.

The overall operative mortality in this survey was $7 \%$ but it is noteworthy that since the last of these deaths occurred in 1966 there have been no postoperative deaths in 14 patients who have had thymectomies since that date.

We wish to thank the Medical Research Committee of the United Liverpool Hospitals and the Liverpool Regional Hospital Board for a research grant in support of this survey.

\section{REFERENCES}

Blalock, A., Harvey, A. McGhee, Ford, F. R., and Lilienthal, J. L. Jnr. (1941). The treatment of myasthenia gravis by removal of the thymus gland. J. Amer. med., Ass. 117, 1529.
Buckberg, G. D., Herrmann, Jr. C., Dillon, J. B., and Mulder, D. G. (1967). A further evaluation of thymectomy for myasthenia gravis. J. thorac. cardiovasc. Surg., 53, 401.

Eaton, L. M., and Clagett, O. T. (1950). Thymectomy in the treatment of myasthenia gravis. J. Amer. med. Ass., $142,963$.

(1955). Present status of thymectomy in treatment of myasthenia gravis. Amer. J. Med., 19, 703.

Grob, D. (1953). Course and management of myasthenia gravis. J. Amer. med. Ass., 153, 529.

Keynes, G. L. (1949). The results of thymectomy in myasthenia gravis. Brit. med. J., 2, 611.

- (1954). Surgery of the thymus gland. Second (and third) thoughts. Lancet, 1, 1197.

Osserman, K. E. (1958). Myasthenia Gravis. Grune and Stratton, New York. Schwab, R. S., Osserman, K. E., Papatestis, A., Alpert L., and Kark, A. (1971). The role of thymectomy in the treatment of myasthenia gravis. Ann. N.Y. Acad. Sci., 183, 308.

Postkanzer, D. C., Schwab, R. S., Viets, H. R., Osserman, K. E., and Genkins, G. (1966). Myasthenia N gravis: evaluation of treatment in 1,355 patients. Neurology (Minneap.), 16, 431.

Ross, R. T. (1952). Thymectomy in the treatment of myasthenia gravis. Lancet, 1, 785.

Simpson, J. A. (1958). An evaluation of thymectomy in myasthenia gravis. Brain, 81, 112.

Viets, H. R., and Schwab, R. S. (1960). Thymectomy for Myasthenia Gravis. Thomas, Springfield, Illinois. 